\title{
A cadeia de carne de frango: uma análise dos mercados brasileiro e mundial de 2002 a $2012^{1}$
}

\author{
Márcia Voila* \\ Divanildo Triches**
}

\begin{abstract}
Resumo
O objetivo deste estudo é analisar a evolução dos mercados brasileiro e mundial da carne de frango no período de 2002 a 2012 e as principais características de sua produção, importação e exportação. A metodologia utilizada baseia-se nos métodos estatísticos e descritivos. Os resultados indicam que a cadeia é altamente estruturada, que a produção nacional de carne de frango está concentrada nos três estados da Região Sul e em São Paulo, o que representa cerca de $70 \%$ do total. O Brasil é o terceiro maior produtor mundial de frangos, com uma participação de $14,1 \%$ e uma taxa anual de crescimento média de 5,3\%. Os Estados Unidos aparecem como principal produtor mundial, mas com queda na sua participação. A produção mundial de carne de frango cresce à taxa média de $4,3 \%$ ao ano. O Brasil e os Estados Unidos são também os principais exportadores mundiais de carne de frango com $72,0 \%$ do total comercializado. Os mercados consumidores de carne são bastante diversificados, dentre os três principais importadores, destacam-se Japão, Arábia Saudita e União Europeia, somando mais de um quinto do total. Por fim, o aumento do consumo tende a ser ocasionado pela preferência da população por carne branca e pela queda dos preços ocorridos ao longo do tempo. Esse fato deu-se, sobretudo, pelo desenvolvimento tecnológico e pelo aumento de escala de produção das empresas produtoras.
\end{abstract}

Palavras-chave: Cadeia produtiva da carne de frango. Análise dos mercados brasileiro e mundial.

* Bacharel em Economia pela Universidade de Caxias do Sul (UCS). E-mail: marcia@multiprado.com.br

** Doutor em Economia pela Universidade Federal do Rio Grande do Sul (UFRGS). Professor do Programa de Pós-Graduação em Economia da Universidade do Vale do Rio dos Sinos (PPGE/Unisinos). Pesquisador CNPq (PQ).E-mails: divanildo@pq.cnpq.br e divanildot@unisinos.br

http://dx.doi.org/10.5335/rtee.v21i44.5357

Submissão: 18/08/2014. Aceite: 03/11/2014. 


\section{Introdução}

Os grandes avanços da pesquisa no desenvolvimento de novas tecnologias no setor da avicultura converteram o Brasil em um dos maiores produtores e exportadores de carne de frango mundiais. Além disso, ocorreram mudanças significativas no padrão alimentar, que fizeram a carne de frango ser uma das mais consumidas, principalmente, nas últimas duas décadas. Outro fator que também contribuiu refere-se à abertura dos mercados, resultado do processo da globalização econômica, que fez com que ocorresse uma elevação na escala de produção, com redução de custos, gerando, portanto, aumento de consumo, conforme Castro (2002).

Contudo, dentre os países com maior relevância na produção de carne de frango, aparecem os Estados Unidos, com aproximadamente um quarto do total mundial, de acordo com informações da Abef (2012). A China ocupa a segunda posição e o Brasil a terceira, participando com $16,6 \%$ e 15,41\% da produção em 2012, respectivamente. Destaca-se que a produção mundial de carne de frango é altamente concentrada, no conjunto, os três países responderam por mais da metade do total da produção.

Assim, o estudo das principais cadeias produtivas de frango, permite identificar as suas principais potencialidades e deficiências. ${ }^{2}$ Além disso, são destacados os aspectos competitivos, as vantagens comparativas regionais e internacionais, os estrangulamentos setoriais e a necessidade da manutenção do dinamismo produtivo, entre outros aspectos de grande relevância para o desenvolvimento da economia local. Outro fator significativo, é que a indústria que compõe o agronegócio tende a ser uma fonte importante de agregação de valor, principalmente, dos produtos para exportação.

A cadeia produtiva da carne de frango apresenta uma trajetória de destaque dentre as cadeias produtivas agroindustriais, sobretudo no Brasil. Ela também é caracterizada, como mostram Castro (2002), Iparede (2002), Oliveira e Gordin (2003), pela utilização de modernos sistemas de planejamento, organização, coordenação dos elos, incorporação de novas tecnologias e técnicas gerenciais que se refletem no constante crescimento da produção.

O estudo de Prochnik e Haguenauer (2001) revela a existência de um vínculo entre o conceito das cadeias produtivas e algumas propostas das teorias de crescimento desequilibrado. As cadeias produtivas resultam da crescente divisão do trabalho e da maior interdependência entre os agentes econômicos. Triches et al. (2004) analisaram a cadeia produtiva da carne de frango da Serra Gaúcha e estimaram, por meio de métodos econométricos, a função demanda por carne de frango

Teoria e Evidência Econômica - Ano 21, n. 44, p. 126-148, jan./jun. 2015 
no período de 1992 a 2003. Os resultados indicaram que a cadeia é altamente estruturada e que os principais atores estão organizados em uma linha de integração vertical. Vieira (2011) analisou a estrutura da cadeia produtiva do frango de corte no estado da Bahia, apresentando suas particularidades e suas inter-relações com os aspectos regionais, sociais e econômicos. O resultado indicou que o estado da Bahia apresenta dois tipos de produção: integrada e independente.

Nesse contexto, o objetivo deste estudo é analisar a evolução dos mercados brasileiro e mundial da carne de frango no período de 2002 a 2012 e as principais características de produção, importação e exportação. Identifica-se e dimensiona-se também a cadeia produtiva de carne de frango no Brasil, demonstrando a produção dos principais estados brasileiros bem como o destino final da carne de frango.

Para tanto, o artigo está organizado em cinco seções, além da introdução. $\mathrm{Na}$ segunda seção, encontram-se os aspectos conceituais da cadeia. A terceira seção traz uma análise do desempenho do setor da carne de frango brasileira e a localização dos principais produtores. Na quarta seção, abordam-se os aspectos relevantes do mercado mundial da carne de frango, como produção, principais produtores, importadores e exportadores mundiais. Por fim, na quinta seção, encontram-se as conclusões.

\section{Cadeia produtiva da avicultura}

A cadeia produtiva de frango é caracterizada por uma sequência de operações que conduzem à produção de bens e pode ser desmembrada em três importantes áreas: a) produção de insumos, b) industrialização, e c) comercialização e distribuição. A etapa inicial, a de produção, foi definida por Batalha (1997) como a etapa de produção de insumos básicos. Já que o produto final é o frango abatido, a matéria-prima é o próprio frango na sua fase inicial de vida. Esse ciclo diz respeito a todos os agentes envolvidos, desde o nascimento e crescimento dos frangos até a idade do abate. A segunda etapa refere-se à industrialização, caracterizada pelos abatedouros, denominados também de frigoríficos, elo principal da cadeia. $\mathrm{O}$ terceiro e último elo da cadeia é a comercialização/distribuição, representado pelas empresas que estão relacionadas diretamente com o consumidor final, viabilizando o comércio e o consumo dos produtos finais. Essas empresas distribuidoras são atacadistas, as grandes e pequenas redes de supermercados, os açougues, os pequenos estabelecimentos varejistas, além de todo aparato que envolve as negociações do mercado internacional para exportação. 
A cadeia produtiva da avicultura é então caracterizada, conforme o esquema apresentado na Figura 1, por elos principais: avozeiro, matrizeiro, incubatório/ nascedouro, aviário, frigorífico, varejista e consumidor final, e por elos auxiliares: pesquisa e desenvolvimento genético, medicamentos, milho, soja e outros insumos, equipamentos e embalagens.

Figura 1 - Representação da cadeia produtiva da avicultura

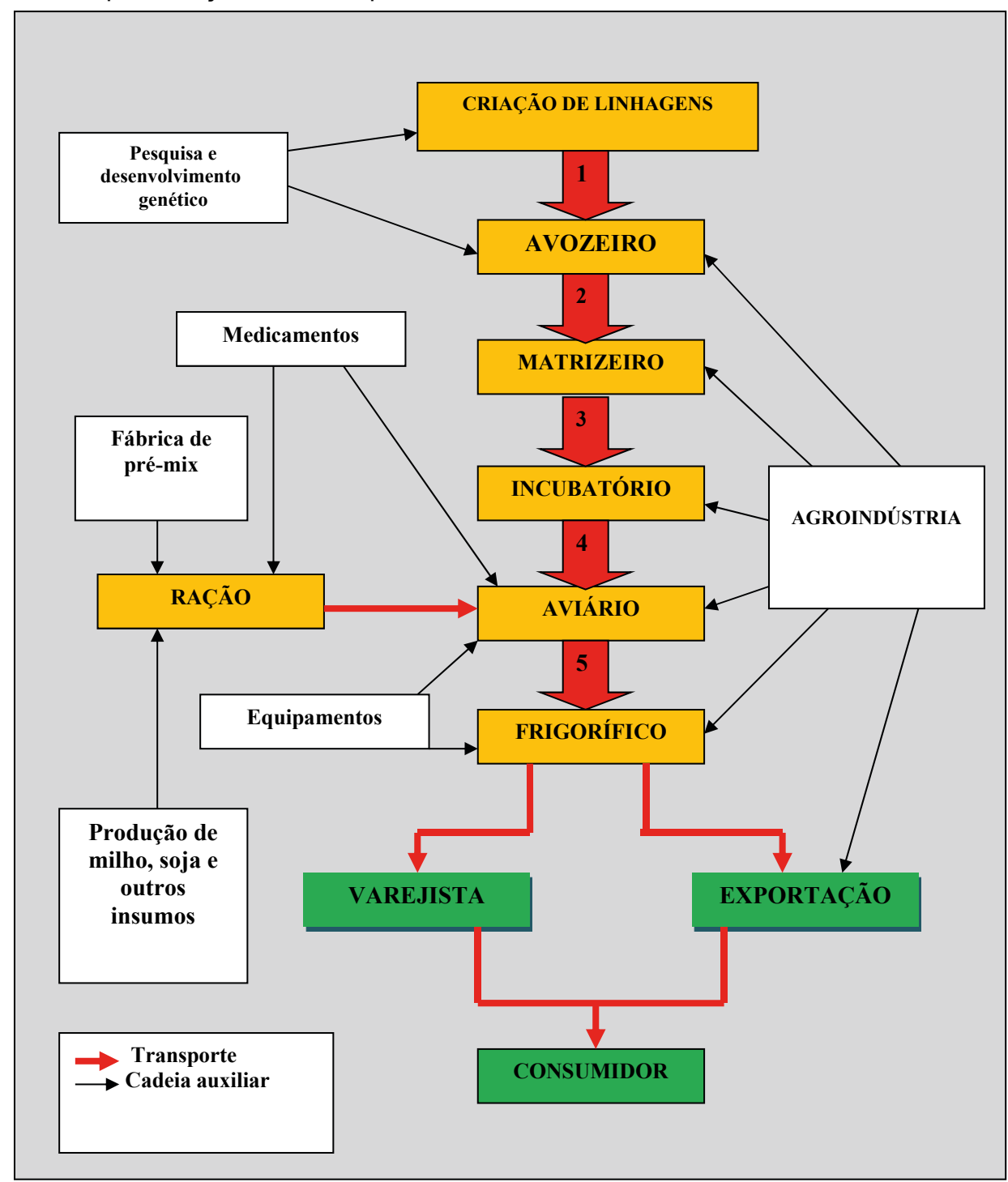

Fonte: adaptado de Triches et al. (2004, p. 6). 
O avozeiro é o primeiro elo da cadeia produtiva, em que ficam as poedeiras avós, originadas a partir da importação de ovos das linhagens avós, que são cruzadas para produzir as matrizes que, por sua vez, vão gerar os frangos comerciais criados para o abate. $O$ matrizeiro é o segundo elo da cadeia produtiva, pertencente, em geral, à agroindústria, no qual se produzem os ovos. O incubatório/nascedouro é o terceiro elo da cadeia produtiva. Essa unidade também pertence à agroindústria e recebe os ovos para chocá-los. Na sequência do processo, passam para os nascedouros, cujo objetivo é dar origem aos frangos de corte, que serão encaminhados para os aviários após algumas horas de seu nascimento.

O aviário é o quarto elo da cadeia produtiva e corresponde a uma etapa de produção caracterizada pelos contratos de integração entre frigoríficos e produtores. É no aviário que ocorre o crescimento e a engorda dos frangos, onde permanecem até a idade de abate, em média 45 dias. $O$ frigorífico é o quinto elo da cadeia produtiva, é a chamada unidade industrial, abatedouro ou agroindústria, de onde sai o produto final, o frango resfriado, congelado, inteiro e em cortes/pedaços. É composto por várias seções no processo produtivo, como: recepção, atordoamento, sangria, escaldagem, depenagem, evisceração, lavagem, pré-resfriamento, gotejamento, pré-resfriamento de miúdos, processamento de pé, classificação, cortes, embalagem, congelamento e expedição.

Para Castro (2002), as agroindústrias são responsáveis por grande parte da coordenação do funcionamento dessa cadeia produtiva. A partir disso origina-se o segmento varejista, que inclui empresas de distribuição para o mercado interno ou externo. $\mathrm{O}$ atacadista não aparece como um elo individual, porque o próprio frigorífico desempenha esse papel, conforme demostraram Triches et al. (2004).

O último elo da cadeia produtiva é o consumidor, representado tanto pelo mercado nacional como pelo internacional. $\mathrm{O}$ varejo tem feito, ao longo dos últimos quarenta anos, significativos investimentos na expansão da sua rede física e nos sistemas de informação, o que lhe dá grande destaque como setor produtivo da economia nacional.

Estudos empíricos mostram que o Brasil tornou-se o terceiro maior produtor mundial de carne de frango e maior exportador do produto. Melz (2010) apresentou os determinantes da competitividade da cadeia de frango no Mato Grosso, do período de 2005 a 2008 , e concluiu que houve um aumento de $69,94 \%$ no número de aves abatidas nos frigoríficos registrados no Serviço de Inspeção Federal (SIF). Já Braga et al. (2007) analisaram cada um de seus principais elos da cadeia de frango ao longo do período entre 1970 e 2004, apontando ameaças e oportunidades. Os autores mostraram que o sucesso da cadeia produtiva de frango passa por uma 
grande interação com os setores de pesquisa, insumo, produção, transformação e distribuição.

A competitividade da cadeia da carne de frango no Paraná é analisada por Ipardes (2002). O estudo revela que a ela estão relacionados o comércio exterior e as condições macroeconômicas, como taxa de juros, renda e carga tributária. Por último, Vieira, Capacle e Belik (2011) demonstraram os principais elos das cadeias produtivas de frango e bovina no Brasil por meio das diferenças organizacionais e estruturais sob a ótica da Nova Economia Institucional. Os autores indicaram uma grande diferença organizacional entres as cadeias de carne de frango e de carne bovina. A cadeia produtiva do frango de corte tem gerado redução de custos de transação nas operações entre os agentes, além de inibir o comportamento oportunista e as falhas de mercado.

\section{Desempenho do setor da avicultura brasileiro}

A avicultura brasileira desenvolveu-se a partir do final da década de 1950, nos estados da Região Sudeste, principalmente em São Paulo. Esse período foi marcado pelo sistema de produção artesanal, no qual o frango caipira era vendido vivo ou já abatido nas feiras livres ou avícolas. A venda era regionalizada, pois a carne era resfriada com pouco prazo de validade, no máximo dez dias. Mais tarde, a avicultura começou a ganhar escalas industriais com o surgimento dos primeiros abatedouros com maior capacidade. Na década de 1970, houve uma reorganização da produção de carnes no Brasil, tendo a atividade se deslocado para a Região Sul. Criou-se o sistema de integração, em que as empresas firmavam contratos com pequenos agricultores que, em regime de parceria, recebiam assistência técnica, pintinhos, ração, e alguns até financiamento para a construção das instalações dos aviários.

A produção brasileira de carne de frango teve rápido desenvolvimento e elevou a posição do Brasil a um dos principais produtores mundiais. Tal fato se dá, principalmente, devido às condições climáticas favoráveis e às vantagens comparativas encontradas no território brasileiro. A Figura 2 apresenta a produção de carne de frango no Brasil no período de 2002 a 2012. Nota-se que a produção passou de 7.050 milhões de toneladas, em 2002, para 10.692 milhões de toneladas, em 2010. Isso representa, ao longo do período, uma taxa média anual de crescimento de $5,34 \%$ ao ano. 
Em 2005 e 2006, em consequência do foco de gripe aviária, houve uma queda da produção na média dos dois anos de 7,53\%. Já em 2008 a produção apresentou o maior crescimento durante todo o período estudado, ou seja, $13,65 \%$ em comparação ao ano anterior, cujo total fora de 10.215 milhões de toneladas. Em outubro de 2008, houve o impacto da crise econômica, tal fato fez com que o ano de 2009 tivesse uma queda de 2,7\%, prejudicando assim o crescimento da produção. Em 2010, o país voltou a apresentar crescimento, que foi impulsionado pelo aumento do consumo de carne de frango e pela expansão nas exportações.

Figura 2 - Produção da carne de frango no Brasil, no período de 2002 a 2012 (em milhões de ton.)

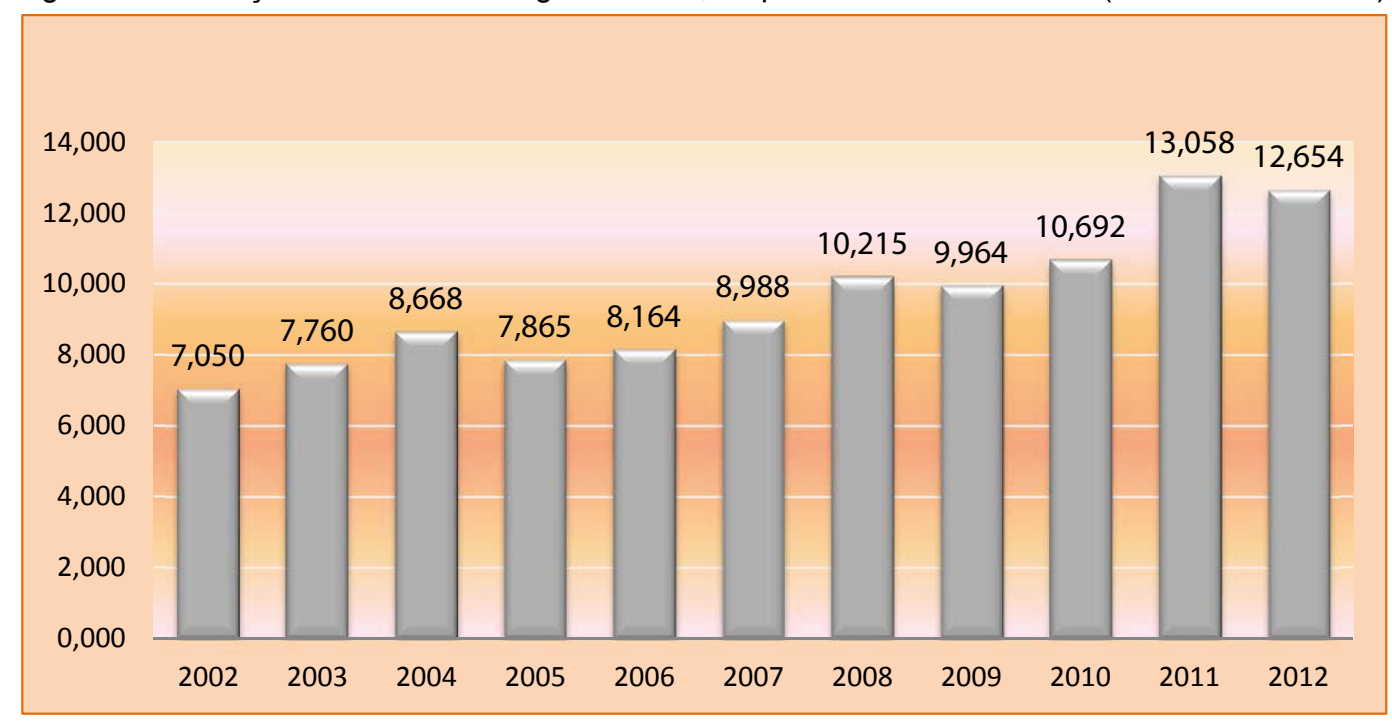

Fonte: FAO, 2012.

A produção da carne de frango no Brasil chegou a 13.058 milhões de toneladas em 2011, um crescimento de 22,8\% em comparação ao ano de 2010. Esse crescimento ocorreu devido ao aumento do consumo per capita. Em 2012, houve uma queda de $3,17 \%$ na produção brasileira de frangos, com 12.645 milhões de toneladas. Essa queda deveu-se à estiagem ocorrida no sul do país, que provocou a escassez de soja além da quebra da safra de milho norte-americana, que originou a elevação dos preços dos cereais. 
Figura 3 - Número de cabeças abatidas e peso dos frangos, período 2002 a 2012

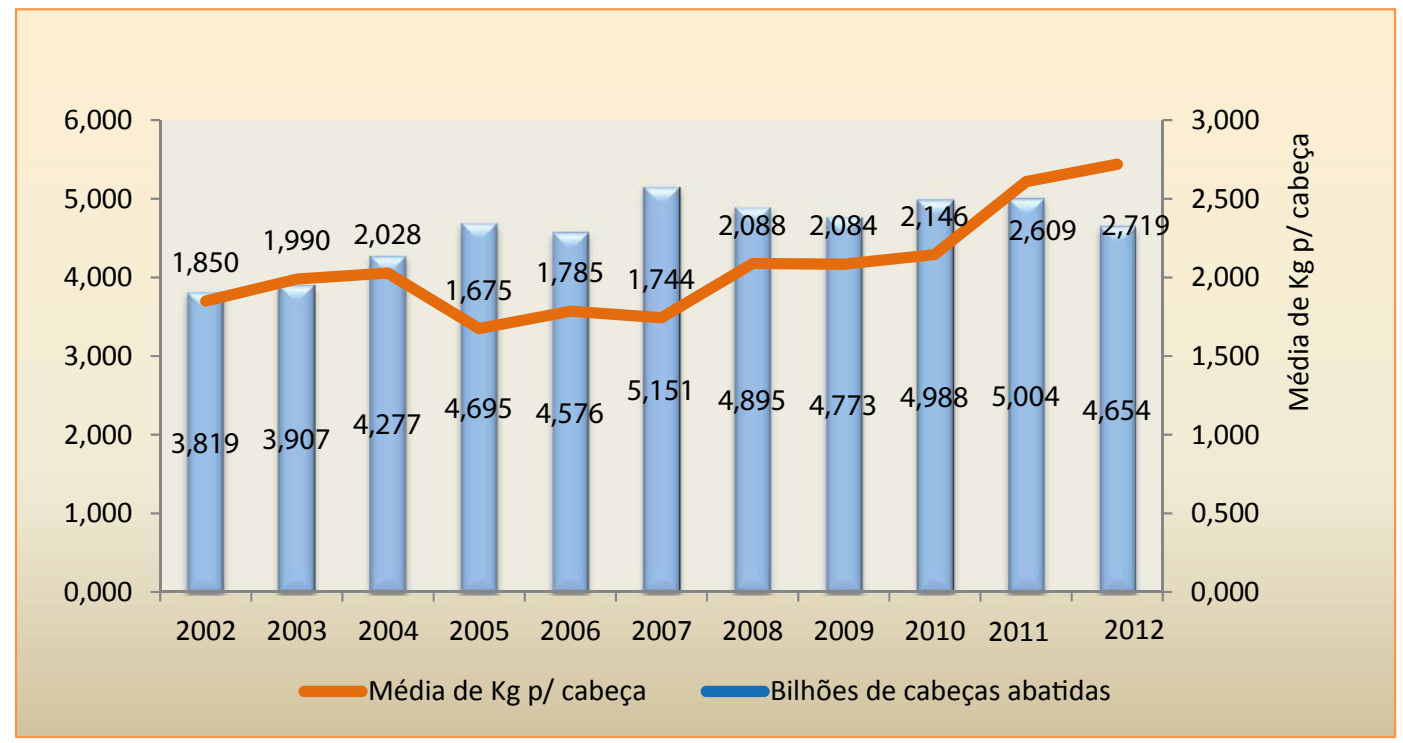

Fonte: FAO, 2012.

A principal preocupação dos produtores ao longo do tempo é aumentar o peso médio e melhorar a qualidade das aves a serem abatidas, visando a o maior rendimento da atividade industrial e ao atendimento da exigência do mercado comprador. Na Figura 3, pode-se observar o crescimento do número de cabeças abatidas ao longo do período entre 2002 e 2010 . A taxa média anual de crescimento foi de $3,39 \%$ ao ano. O número de cabeças abatidas em 2002 era de 3.819 bilhões, e o peso de cada ave era de 1,850 quilo por cabeça.

O número de cabeças abatidas passou para 4.654 bilhões, e o peso da ave passou para 2,719 quilos por frango em 2012. Isso representa, no período de 2002 a 2012 , um crescimento médio, por ordem, de $3,92 \%$ e $2,00 \%$ ao ano. Salienta-se que o recorde de abate deu-se em 2007 com 5.151 bilhões, ou seja, cerca de 12,6\% a mais do que foi registrado no ano anterior. A crise financeira internacional de 2008 afetou o segmento da avicultura brasileira, pois houve queda de quase 380 milhões de frangos abatidos, ou $7,3 \%$, em 2009 , se comparado a dois anos anteriores. O número de cabeças abatidas de frangos ultrapassou novamente a marca dos 5 bilhões em 2011, mas decresceu para 35 milhões no ano seguinte.

A Figura 4 ilustra a evolução do consumo de frango per capita no Brasil de 2002 a 2012. Observa-se que o consumo passou de 33, 810 quilos por habitante, em 2002, para 45 quilos em 2012, um crescimento médio de 2,90\% ao ano. Em 2005 e 
2006, mesmo com as suspeitas da gripe aviária, o consumo manteve-se na faixa dos 35 quilos. O grande saldo no consumo per capita deu-se em 2011, quando aumentou para 43,380 quilos, ante os 38,470 registrados em 2009, com uma elevação de $13 \%$.

Figura 4 - Evolução do consumo de frango per capita no Brasil entre 2002 e 2012 (em kg)

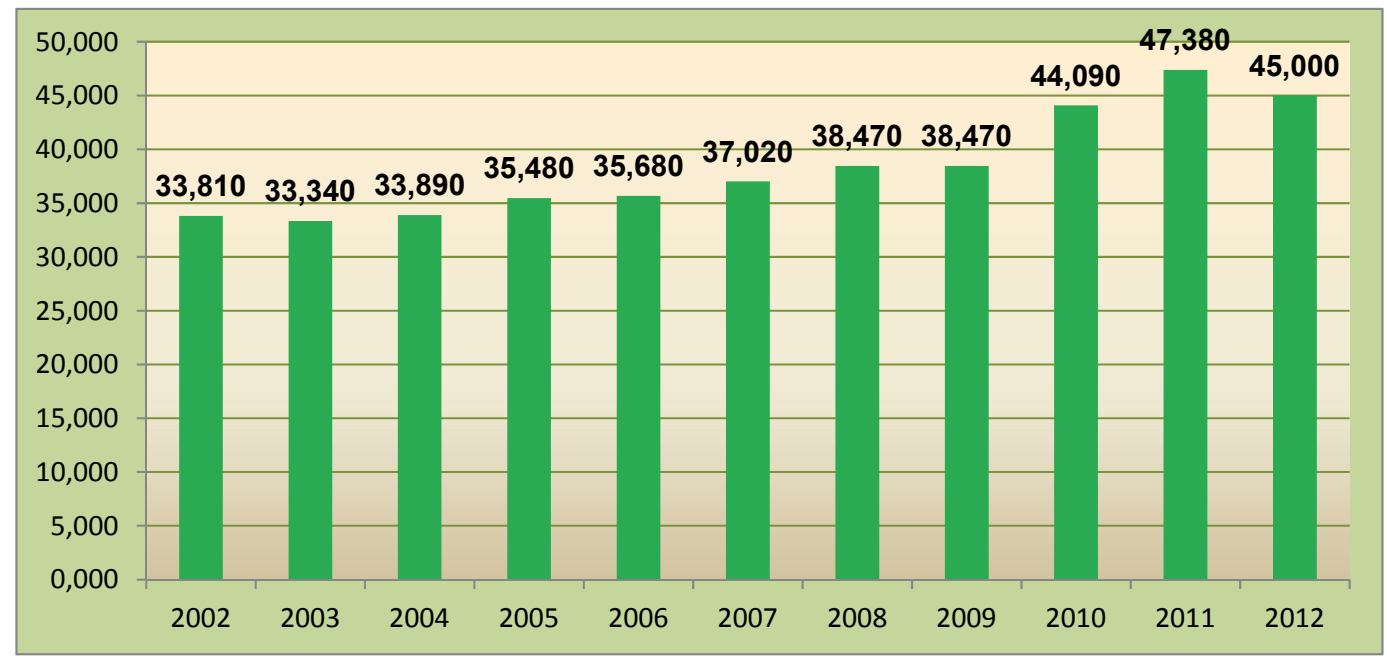

Fonte: UBA 2014.

Segundo Triches et al. (2004), o aumento do consumo da carne de frango está associado a quatro fatores básicos: a) a substituição das carnes vermelhas, em decorrência, principalmente, da crescente preocupação com a saúde e a ordem ambiental; b) melhor capacidade de coordenação da cadeia agroindustrial do frango aliado ao baixo preço, se comparado às outras carnes, além de constante desenvolvimento de novos produtos e marcas; c) grande aceitação da carne de frango pela maioria da população; d) crescentes ganhos de produtividade na indústria da carne de frango devido às melhorias tecnológicas.

As agroindústrias vinculadas à avicultura, como os grandes abatedouros e frigoríficos, estão concentradas principalmente na Região Sul, expandindo-se para a Região Sudeste e, mais recentemente, para a Região Centro-Oeste, em busca de oferta e de novas fronteiras agrícolas. Em todas as regiões, a diferenciação no nível de tecnologia de algumas empresas permite a produção de cortes de frango com alto grau de padronização, oferecendo ao mercado um produto de maior valor agregado. 
Tabela 1 - Número de frangos abatidos por empresa no período de 2003 a 2011 (mil cabeças)

\begin{tabular}{l|r|r|r|r|r|r|r}
\hline \multicolumn{1}{c|}{ Empresas } & \multicolumn{1}{c|}{2003} & \multicolumn{1}{c|}{$\%$} & \multicolumn{1}{c|}{2007} & \multicolumn{1}{c|}{$\%$} & 2011 & \multicolumn{1}{c}{$\begin{array}{c}\operatorname{Var}^{* *} . \\
(\%)\end{array}$} \\
\hline Sadia* & 479.901 & 12,3 & 929.058 & 18,0 & 1.756 .000 & 32,3 & 8,6 \\
Perdigão* & 427.440 & 10,9 & 605.209 & 11,7 & & & \\
Seara & 246.151 & 6,3 & 270.171 & 5,2 & 649.000 & 11,9 & 12,9 \\
Frangosul & 237.804 & 6,1 & 255.941 & 5,0 & 275.800 & 5,8 & 1,9 \\
Aurora & 87.567 & 2,2 & 113.813 & 2,2 & 142.400 & 2,6 & 6,3 \\
Dagranja & 95.785 & 2,5 & 104.234 & 2,0 & 125.200 & 2,3 & 3,4 \\
Big Frango & 41.892 & 1,12 & 75.888 & 1,5 & 113.700 & 2,1 & 13,3 \\
Penabranca & 72.163 & 1,8 & 71.623 & 1,4 & 98.500 & 1,9 & 4,0 \\
Copacol & 56.438 & 1,4 & 69.890 & 1,4 & 91.000 & 1,7 & 6,2 \\
Pif Paf & 48.561 & 1,2 & 51.252 & 1,0 & 57.000 & 1,0 & 2,0 \\
Outros & 2.113 .298 & 54,1 & 2.604 .921 & 50,6 & 2.131 .912 & 39,2 & 0,1 \\
Total & 3.907 .000 & 100,0 & 5.152 .000 & 100,0 & 5.440 .512 & 100,0 & 4,2 \\
\hline
\end{tabular}

Fonte: UBA 2014.

* A produção de 2011 refere-se a empresa Brasil Foods (BRF) união das empresas Sadia e Perdigão. A taxa de crescimento considera a soma de abate das duas empresa, em 2003 com o valor total de 2011.

** Refere-se à taxa média geométrica de variação anual no período considerado.

Na Tabela 1, pode-se observar as dez maiores empresas brasileiras de abate de frango no período entre 2003 e 2011 . Nota-se que no ano de 2003, o número de cabeças abatidas foi de 3.907 bilhões; já em 2007, o número passou para 5.152 bilhões de cabeças abatidas ${ }^{3}$. Isso representa uma taxa média anual de 7,2\% ao ano. Ao longo do período, nota-se ainda que a primeira colocação em termos de abate de frango é ocupada pela empresa Sadia, com uma participação de 12,3\% do total ou 480 milhões de aves em 2003. Quatro anos mais tarde, a empresa cresceu na participação do total dos abates para $18 \%$, que representa 930 milhões de aves, o que significa $18 \%$ de crescimento médio anual ao longo do período.

O ano de 2010 foi marcado pela fusão das empresas Sadia e Perdigão, que se transformou na Brasil Foods S. A., que passou a deter quase 30\% do total do mercado, no ano seguinte passou a 32,3\%. O terceiro lugar, atualmente o segundo, foi mantido pela empresa Seara, que passou de $6,3 \%$, em 2003, para 11,9\% de participação total em 2011, ou seja, o total de abates cresceu de 246 milhões para 649 milhões. A empresa com maior taxa de crescimento no número de frangos abatidos foi a Big Frango, com uma taxa média anual de 13,3\% ao ano. Em 2003, a empresa abatia 42 milhões de frangos, em 2011, o número passou para 113,7 milhões. Destaca-se que quase todas as empresas selecionadas apresentaram taxa de crescimento médio anual bem acima da nacional, que foi de $4,2 \%$ no período. 
O número total de abates de frango por estado brasileiro, no período de 2003 a 2011, encontra-se na Tabela 2. Nota-se que o Paraná apareceu na primeira colocação, com mais de $20 \%$ do total, ou 813 milhões de aves abatidas em 2003, e cresceu para $28,4 \%$ do total oito anos mais tarde, abatendo 1.545 bilhão de aves. Ao longo do período, o estado registrou uma taxa média anual de $8,4 \%$, ou o dobro da média nacional. A segunda posição era ocupada por Santa Catarina, com mais de 16\% do total de abates, ou 649 milhões de aves em 2003. Já em 2011, esse número passou para 979 milhões, o que representou uma taxa média anual de 5,3\% ao ano. O estado do Rio Grande do Sul apareceu em terceiro lugar, com 826 milhões de frangos abatidos em 2009 e taxa média anual de $4 \%$ ao ano.

As unidades da federação que mais se destacaram em termos de taxa média anual de crescimento de abates de frango foram Mato Grosso, Distrito Federal e Goiás. O primeiro passou de 66,3 milhões de aves abatidas em 2003 para 322,2 milhões oito anos mais tarde, registrando uma taxa média de 15,6\% ao ano, ou seja, 11,4 pontos percentuais acima da média brasileira. O Distrito Federal, no mesmo período, cresceu de 31,5 milhões para 87 milhões, uma taxa média positiva de $13,5 \%$ ao ano. Goiás, por sua vez, passou de 138 milhões de aves abatidas em 2003 para 326,4 milhões em 2011, uma média de 11,4\% ao ano. A menor taxa média de crescimento foi registrada por Pernambuco, com uma queda de 6,5\% ao ano.

Tabela 2 - Abate de frangos por estado brasileiro no período 2003 a 2011 (mil cabeças)

\begin{tabular}{|c|c|c|c|c|c|c|c|}
\hline Estados & 2003 & $\%$ & 2009 & $\%$ & 2011 & $\%$ & $\operatorname{Var} .(\%)^{*}$ \\
\hline Paraná & 813.374 & 20,8 & 1.243 .245 & 26,0 & 1.545 .105 & 28,4 & 8,4 \\
\hline Santa Catarina & 648.752 & 16,6 & 871.156 & 18,2 & 979.292 & 18,0 & 5,3 \\
\hline Rio Grande do Sul & 602.214 & 15,4 & 758.951 & 15,9 & 826.958 & 15,2 & 4,0 \\
\hline São Paulo & 467.215 & 12,0 & 659.382 & 13,8 & 788.874 & 14,5 & 6,8 \\
\hline Minas Gerais & 233.045 & 6,0 & 363.219 & 7,6 & 369.955 & 6,8 & 5,9 \\
\hline Goiás & 138.022 & 3,5 & 271.309 & 5,7 & 326.431 & 6,0 & 11,4 \\
\hline Mato Grosso & 66.332 & 1,7 & 150.322 & 3,1 & 212.180 & 3,9 & 15,6 \\
\hline Mato Grosso do Sul & 112.087 & 2,9 & 128.614 & 2,7 & 157.775 & 2,9 & 4,4 \\
\hline Distrito Federal & 31.506 & 0,8 & 72.514 & 1,5 & 87.048 & 1,6 & 13,5 \\
\hline Bahia & 33.228 & 0,9 & 64.598 & 1,4 & 32.643 & 0,6 & $-0,2$ \\
\hline Pernambuco & 37.140 & 1,0 & 51.644 & 1,1 & 21.762 & 0,4 & $-6,5$ \\
\hline Outros & 223.804 & 5,7 & 8.550 & 0,2 & 272.550 & 5 & 2,5 \\
\hline Abate S/SIF & 500.281 & 12,8 & 130.496 & 2,7 & 146.894 & 2,7 & $-14,2$ \\
\hline Total & 3.907 .000 & 100,0 & 4.774 .000 & 100,0 & 5.440 .512 & 100,0 & 4,2 \\
\hline
\end{tabular}

Fonte: UBA, 2014.

* Refere-se à taxa média geométrica de variação anual. 
Nesse período, os destinos das exportações brasileiras de carne de frango aumentaram de maneira significativa, passando de 125 países em 2003, para 158 países em 2006 , e para mais de 170 países em $2010 .{ }^{4}$ Os principais destinos, no período de 2002 a 2011, encontram-se ilustrados na Figura 5. Observa-se que, embora a carne de frango brasileira tenha conquistado muitos mercados externos, as suas exportações estão bastante concentradas. Somente o Oriente Médio detém cerca de um terço do total da pauta. As vendas para essa região passaram de 458 mil toneladas, em 2002, para 1.413 milhão de toneladas nove anos mais tarde, representando uma taxa média de crescimento de $13,3 \%$ ao ano, ao longo do período.

O segundo destino mais relevante das exportações brasileiras de carne de frango foi para o mercado asiático, que demandou $23 \%$ das exportações em 2002, representando 345 mil toneladas. Já em 2011, esse mercado cresceu para 29\% das exportações, um total de 1.141 milhão de toneladas. Tal fato representa um crescimento médio de mais de $14,2 \%$ ao ano.

A União Europeia (UE), por sua vez, caracterizou-se, em 2002, como o terceiro maior comprador, com $18,2 \%$ do total da pauta de exportações brasileiras de frango. Em 2011, essa região reduziu a demanda por carne de frango brasileira e passou para quarto lugar, com uma proporção de $12,4 \%$ do total. O continente africano, em 2002, ocupava a quinta posição, com $5,1 \%$ da pauta das exportações de carne de frango, perfazendo um total de 76 mil toneladas. Nove anos mais tarde, passou para o terceiro lugar, com um crescimento considerável de consumo de frango brasileiro, totalizando 498 mil toneladas, ou $12,8 \%$ do total. Em termos de crescimento médio anual, essa evolução representa uma elevada taxa de $23,2 \%$ ao ano.

Figura 5 - Destino das exportações brasileiras da carne de frango, no período 2002 e 2011 (\%)
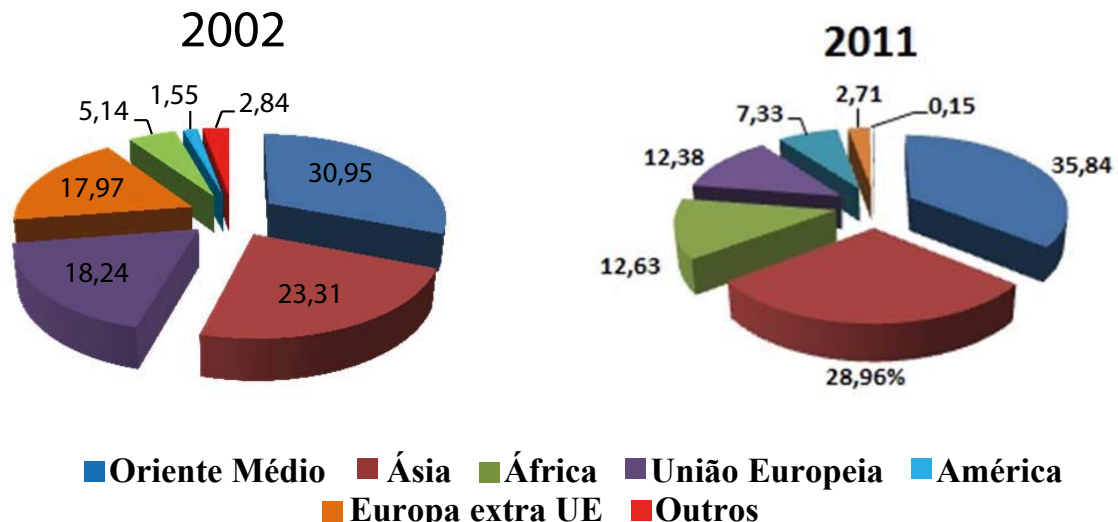

Fonte: Abef, 2012. 
Nota-se ainda na Figura 5 que, em 2011, a América ocupava o quinto lugar, com $7,3 \%$ da pauta das exportações brasileiras de carne de frango, representando um total de 289 mil toneladas. Em 2002, o continente americano detinha a sexta posição, com apenas 1,5\% das exportações, um total de 23 mil toneladas de frango. Ao longo do período, a demanda por carne de frango cresceu significativamente, com uma taxa média anual de mais de $32 \%$ ao ano. Já a Europa, excluindo os países da União Europeia, em 2002, ocupava o quarto lugar, com $18 \%$ da pauta, com um total de 266 mil toneladas, e passou para sexto lugar, com apenas $2,7 \%$ das exportações oito anos mais tarde.

\section{Análise do mercado mundial da carne de frango}

A produção mundial de carne de frango no ano de 2002 foi de 54.1 milhões de toneladas, como mostra a Figura 6. Em 2012, essa produção passou para 82,3 milhões de toneladas de frango. A taxa média de crescimento da produção mundial foi de $4,3 \%$ ao ano, um crescimento acumulado de $52 \%$ ao longo do período. Nota-se também que o maior aumento na taxa de crescimento ocorreu em 2007 - 12,75\% -, se comparado ao ano anterior. Sob o impacto da crise econômica mundial ocorrida a partir de outubro de 2008, a produção mundial de carne de frango registrou um leve crescimento de $0,65 \%$ ao ano em 2009 . No ano seguinte, a produção elevou-se cerca de $6 \%$ em relação ao período imediatamente anterior.

Figura 6 - Evolução da produção mundial da carne de frango no período de 2002 a 2012 (em milhões de ton.)

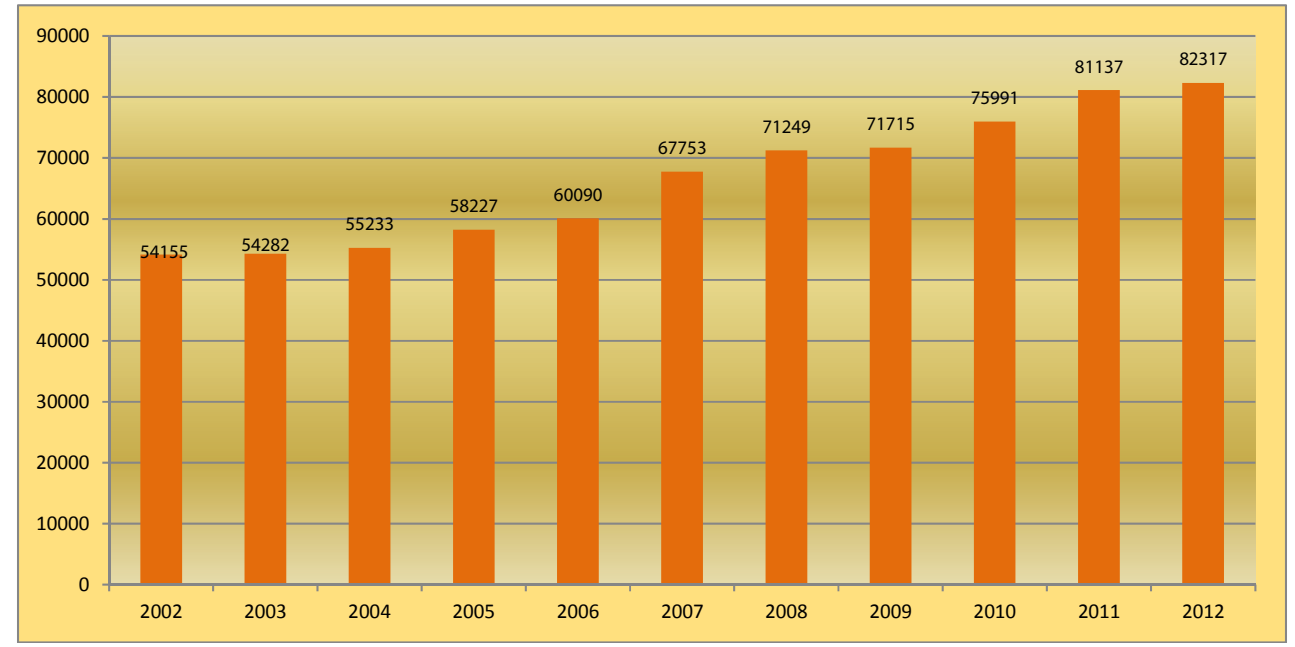

Fonte: Abef (2014). 
Os principais países produtores de carne de frango ao longo do período de 2002 a 2012 estão ilustrados na Tabela 3. Destaca-se que as maiores taxas médias anuais de crescimento foram registradas pelo conjunto de outros países e pelo Brasil, com $6,63 \%$ e 6,02\% ao ano, respectivamente, bem acima, portanto, da média mundial. Em seguida, aparecem México, com 3,89\%, China, com 3,67\%, e União Europeia, com 3,40\%. Dentre os maiores produtores, os Estados Unidos apareceram em primeiro lugar, com $26,7 \%$ do total mundial, ou 14.5 milhões de toneladas, em 2002, passando para 16,5 milhões de toneladas, ou $20 \%$ do total, dez anos após, uma redução de 6,7 pontos percentuais na participação total. A China e o Brasil ocuparam a segunda e a terceira posição, participando com $17,6 \%$ e $13,0 \%$ da produção total mundial de carne de frango, em 2002, respectivamente. Essas participações passaram, na ordem, oito anos mais tarde, para $16,6 \%$ e $15,41 \%$, o que corresponde a 13.7 e 12.6 milhões de toneladas produzidas. Os primeiros três países, em conjunto, responderam por $52 \%$ da produção mundial de carne de frango, o que demonstra uma alta concentração de mercado.

Outros países detinham, ainda de acordo com a Tabela 3, 26,1\% do total mundial de carne de frango produzida em 2002 e passaram para 32,6\% em 2012, o que representa um crescimento de cerca de 6 pontos percentuais na participação. O México aparece com um leve decréscimo na proporção da produção mundial, passando de $4 \%$ para 3,8\% ao longo do período entre 2002 e 2012. Esse comportamento também é observado para o total da União Europeia, cuja perda da participação foi de um ponto percentual.

Tabela 3 - Principais países produtores de frango ao longo do período de 2002 a 2012 (milhões de ton.)

\begin{tabular}{|c|c|c|c|c|c|c|c|}
\hline País & 2002 & $\%$ & 2006 & $\%$ & 2012 & $\%$ & Var. $(\%)^{\star}$ \\
\hline EUA & 14.467 & 26,71 & 16.162 & 26,90 & 16.476 & 20,02 & 1,31 \\
\hline China & 9.558 & 17,65 & 10.350 & 17,22 & 13.700 & 16,64 & 3,67 \\
\hline Brasil & 7.050 & 13,02 & 8.164 & 13,59 & 12.645 & 15,36 & 6,02 \\
\hline UE & 6.788 & 12,53 & 7.425 & 12,36 & 9.480 & 11,52 & 3,40 \\
\hline México & 2.157 & 3,98 & 2.610 & 4,34 & 3.160 & 3,84 & 3,89 \\
\hline Outros & 14.135 & 26,10 & 15.379 & 25,59 & 26.856 & 32,63 & 6,63 \\
\hline Total & 54.155 & 100,0 & 60.090 & 100,0 & 82.317 & 100,0 & 4,28 \\
\hline
\end{tabular}

Fonte: Abef (2014).

* Refere-se à taxa média geométrica de variação no período considerado.

No que concerne às importações de carne de frango verificadas no decorrer do período de 2002 a 2012, ilustradas na Tabela 4, observa-se que em 2002 as importações correspondiam a algo em torno de 4.4 milhões de toneladas, já em 2012, as 
importações passaram para quase 8.5 milhões de toneladas. Esse resultado representou uma taxa de crescimento média anual de 6,7\%. Nota-se ainda que os cinco principais países importadores de carne de frango responderam por $70 \%$ do total importando em 2002, e reduziram substancialmente essa proporção para perto de $40 \%$, o que vem a demonstrar um crescimento na desconcentração das importações. Esse resultado também é ilustrado pelas taxas médias anuais de crescimento registradas pelo conjunto de outros países, que foram de 16,5\%, cuja participação no total era de $31,1 \%$, em 2002 , e cresceu para $42,7 \%$ em 2012. A Rússia, que se destacava na primeira posição como maior importadora de frango até 2006 , detendo mais de um quarto do total mundial, reduziu as compras externas, passando, em 2012, para 7,75\%, portanto, caindo para a quarta posição. Isso representou, ao longo do período, uma redução da taxa média de crescimento de mais de $8 \%$ ao ano.

O Japão, que ocupava a segunda posição até 2006, com uma média de $15 \%$ do total das importações mundiais de carne de frango, passou para primeiro lugar em 2012, embora com queda na participação, para 10\%, ou o equivalente a 115 mil toneladas de carne. Em seguida desponta a Arábia Saudita que, em 2002, detinha a terceira colocação, com 391 mil toneladas, e passou para a posição de segundo maior importador, com 750 mil toneladas dez anos mais tarde. Esse país apresentou a segunda maior taxa de crescimento médio anual, de 6,7\%.

Tabela 4 - Principais países importadores de frango no período de 2002 a 2012 (em mil ton.)

\begin{tabular}{|c|c|c|c|c|c|c|c|}
\hline País & 2002 & $\%$ & 2006 & $\%$ & 2012 & $\%$ & Var. (\%) * \\
\hline Japão & 744 & 16,75 & 740 & 14,32 & 855 & 10,04 & 1,40 \\
\hline Arábia Saudita & 391 & 8,80 & 434 & 8,40 & 750 & 8,81 & 6,73 \\
\hline eu & 500 & 11,25 & 600 & 11,61 & 740 & 8,69 & 4,00 \\
\hline Rússia & 1.208 & 27,19 & 1.240 & 23,99 & 660 & 7,75 & $-5,87$ \\
\hline México & 219 & 4,93 & 400 & 7,74 & 630 & 7,40 & 11,14 \\
\hline Outros & 1.381 & 31,08 & 1.754 & 33,94 & 4.877 & 57,30 & 13,45 \\
\hline Total & 4.443 & 100,0 & 5.168 & 100,0 & 8.512 & 100,0 & 6,72 \\
\hline
\end{tabular}

Fonte: Abef (2014).

* Refere-se à taxa média geométrica de variação no período considerado.

Na sequência, a União Europeia desponta como a terceira região maior importadora, com 740 mil toneladas de carne de frango ou 8,7\% do total em 2010 . O quinto lugar é ocupado pelo mercado mexicano, com 630 mil toneladas de frango, o que equivale a $7,4 \%$ do total mundial importado. Salienta-se que o México foi o país que registrou a maior taxa média de crescimento entre os demais países analisados, com $11,1 \%$ ao ano. 
Os principais mercados nacionais exportadores de carne de frango no período de 2002 a 2012 encontram-se listados na Tabela 5. Percebe-se que as exportações mundiais de carne de frango cresceram à taxa média anual de $6,09 \%$ no período de dez anos, passando de 5.702 milhões de toneladas, em 2002, para 10,301 milhões de toneladas em 2012. Os Estados Unidos apareciam, em 2002, na primeira posição, com 38,2\% do total, ou 2,2 mil toneladas, e o Brasil, na segunda, com 26\%. Esses dois países participavam com quase dois terços do total das exportações. Essas posições foram invertidas dez anos mais tarde, o Brasil passou a ocupar a primeira posição e os Estados Unidos a segunda, com 38\% e 31,2\%, respectivamente. Com isso, a concentração do mercado mundial exportador cresceu ainda mais, em aproximadamente $70 \%$ do total. Salienta-se que o mercado brasileiro foi o principal responsável por esse fato. O Brasil registrou uma taxa de crescimento média anual das exportações de carne de frango de 10,2\%, ou seja, quase o dobro da taxa média mundial. Ainda, em 2002, a carne de frango brasileira registrou uma marca histórica, pois passou a ser comercializada para mais de cem países.

Tabela 5 - Principais países exportadores de frango no período de 2002 a 2012 (em mil ton.)

\begin{tabular}{l|r|r|r|r|r|r|r}
\hline \multicolumn{1}{c|}{ País } & \multicolumn{1}{c|}{2002} & \multicolumn{1}{c|}{$\%$} & \multicolumn{1}{c|}{2006} & \multicolumn{1}{c|}{$\%$} & \multicolumn{1}{c|}{2012} & \multicolumn{1}{c}{$\%$} & Var. (\%) * $^{*}$ \\
\hline Brasil & 1.480 & 25,96 & 2.367 & 36,58 & 3.918 & 38,04 & 10,23 \\
EUA & 2.180 & 38,23 & 2.254 & 34,84 & 3.211 & 31,17 & 3,95 \\
eu & 871 & 15,28 & 820 & 12,67 & 1.080 & 10,48 & 2,17 \\
Tailândia & 427 & 7,49 & 280 & 4,33 & 540 & 5,24 & 2,38 \\
China & 438 & 7,68 & 350 & 5,41 & 400 & 3,88 & $-0,90$ \\
Demais & 306 & 5,37 & 399 & 6,17 & 1.152 & 11,18 & 14,18 \\
Total & 5.702 & 100,0 & 6.470 & 100,0 & 10.301 & 100,0 & 6,09 \\
\hline
\end{tabular}

Fonte: Abef (2014).

* Refere-se à taxa média geométrica.

A União Europeia deteve a terceira posição como maior mercado exportador da carne de frango. Em 2002, a região participava com 15,3\% do total, que representava 871 mil toneladas de carne. Essa proporção caiu, dez anos mais tarde, para 10,5\% do total, resultando uma taxa média de crescimento anual abaixo da média mundial em quase quatro pontos percentuais. Em seguida, aparecem a Tailândia e a China, que também perderam participação no volume mundial exportado, na ordem, de 7,5\% e de 7,7\% do total, em 2002, para 5,2\% e para 43,9\% em 2012. Salienta-se que o mercado chinês foi o único entre os cinco principais exportadores mundiais que registrou taxa média de crescimento negativa de $0,9 \%$ ao ano. Esse fato pode ser explicado pelo surgimento de focos da gripe aviária em países 
asiáticos no inicio de 2006. Por último, os demais países participam tiveram média de participação de 6\%, o que confirma o elevadíssimo grau de concentração do mercado exportador da carne de frango.

O comércio mundial de frango é dominado por grandes empresas multinacionais, localizadas principalmente nos Estados Unidos. As empresas daquele país são caracterizadas como integradores, porque seu processo produtivo apresenta um elevado grau de integração verticalizada. Isso significa que as empresas controlam todas as fases da operação. Os integradores coordenam o fornecimento de frangos por meio de um sistema de contratos com os produtores, avicultores.

Dez empresas mundiais, produtoras de carne frango no ano de 2010 estão reportadas na Tabela 6. Observa-se que a maior empresa produtora de carne de frangos é a norte-americana Tyson Foods, que detinha 5,6\% do total da produção, o que representava 4,30 milhões de toneladas de carne de frango. As três posições seguintes são ocupadas por empresas situadas no Brasil. A JBS Pilgrim's participa com 4,6\% do total produzido. A terceira posição ficou com Brasil Foods, com 2,2\% ou equivalente a 1.70 milhão de tonelada. Essa empresa resultou da união, em meados de 2009, de grandes empresas brasileiras, a Perdigão S.A. e a Sadia S.A. Em quarto lugar, encontra-se a Marfrig, com uma produção de 1.450 milhão de toneladas, que representa 1,9\% do total. A soma das dez maiores empresas produtoras de frango são responsáveis por $21,6 \%$ do total mundial produzido no ano de 2010 . As demais empresas representam $78,3 \%$ do total da produção mundial.

Tabela 6 - Empresas mundiais selecionadas e produtoras de frango no ano de 2010* (em mil ton.)

\begin{tabular}{l|l|c|c}
\hline \multicolumn{1}{c|}{ Empresa } & \multicolumn{1}{|c|}{ Localização } & Produção & $\%$ \\
\hline Tyson Foods & EUA & 4.300 & 5,66 \\
JBS Pilgrim's & Brasil & 3.500 & 4,61 \\
Brasil Foods S.A. - BRF & Brasil & 1.700 & 2,24 \\
Marfrig & Brasil & 1.450 & 1,91 \\
Perdue & EUA & 1.300 & 1,71 \\
Sanderson Farms & EUA & 1.200 & 1,58 \\
Koch Farms & EUA & 800 & 1,05 \\
Wayne Farms & EUA & 750 & 0,99 \\
Moutaine Farms & EUA & 740 & 0,97 \\
Doux & França & 710 & 0,93 \\
Outros & \multicolumn{2}{|c}{} \\
Total no mundo & \multicolumn{2}{|c}{} \\
\hline
\end{tabular}

Fonte: AVEWORLD, 2012.

* Somente este ano que foram obtidas as informações de produção. 
Em síntese, o mercado mundial de carne de frango tem se caracterizado pelo aumento do consumo, em função do crescimento da demanda da população e pela redução dos preços ocorridos ao longo do tempo. Nas exportações, no ano de 2010 , o Brasil está em primeiro lugar, seguido pelos Estados Unidos, que de 2002 a 2004 permaneceram em primeiro lugar. A produção mundial de carne de frango está associada a novas tecnologias utilizadas pelas empresas, que promovem a redução dos custos de produção e geram assim aumento da produtividade.

\section{Conclusões}

A análise da cadeia produtiva da avicultura permitiu verificar a inter-relação existente entre os elos que a compõem e, principalmente, os benefícios dessa diversificação. Além disso, é caracterizada pela utilização de modernos sistemas de planejamento, organização, coordenação e incorporação de novas tecnológicas e técnicas gerenciais que se refletem no constante crescimento da produção. O mercado da carne de frango aponta um forte dinamismo no seu crescimento e a carne deixou de ser restrita ao consumo das classes sociais de níveis mais elevados. $\mathrm{O}$ setor também tem sido beneficiado pela conjuntura internacional favorável com crescimento da demanda mundial, especialmente nos mercados dos países do Oriente Médio e da Ásia Oriental.

A produção brasileira de carne de frango, no período de 2002 a 2010, registrou uma taxa média anual de crescimento de 5,3\%. Esse crescimento ocorreu devido às condições climáticas favoráveis e à matéria-prima, também em razão de um sistema de integração com pequenos produtores rurais que foi desenvolvido pelas agroindústrias. A produção está altamente concentrada nos estados da Região Sul e em São Paulo que, em conjunto, respondem por cerca de 70\% do total do abate de frango do país. Os estados do Paraná, Santa Catarina e Rio Grande do Sul são os maiores produtores nacionais. Os resultados demonstram que com a fusão das empresas Sadia e Perdigão, a empresa Brasil Foods S. A. passou a deter quase um terço do total do mercado. Contudo, a Big Frango constituiu-se na empresa com maior taxa de crescimento, com $16 \%$ ao ano.

Quanto aos destinos das exportações brasileiras de carne de frango, embora elas aumentem de maneira significativa, exportando para mais de 170 países, as vendas externas são bastante concentradas. Apenas o Oriente Médio detém cerca de um terço do total da pauta. Nesse sentido, ações em parceria com agências governamentais e com o próprio governo realizam prospecções de novos mercados e a diversificação do montante exportado. 
Apesar disso, o segmento de carne de frango enfrenta vários desafios para manter a competividade internacional, como taxa de câmbio desfavorável, aumento do custo de insumos, escassos incentivos governamentais. Portanto, há necessidade de mais empenho do governo quanto aos investimentos em infraestrutura viária e à redução da carga tributária, que implique na redução dos custos internos. Isso estimularia a gestão empresarial da cadeia na otimização de recursos para investimentos em pesquisas em estrutura produtiva e qualificação profissional, com geração de empregos e aumento da inserção internacional. Há também um possível risco de desabastecimento de matérias-primas para produção de ração, em função da possível utilização do milho como matéria-prima para produção de etanol e da soja para biodiesel.

Em síntese, enfatiza-se que a posição de destaque assumida pelo Brasil como mercado exportador de carne de frango, deve-se a diversos fatores. Dentre eles estão: a) as mudanças nos fluxos de comércio motivadas por ocorrências sanitárias, como a vaca louca, no Canadá e nos Estados Unidos, em 2003; b) o surgimento da gripe aviária em países asiáticos, como Tailândia, Vietnã, China, e em países de outros continentes, como Estados Unidos e Canadá; c) o avanço tecnológico e melhorias no processo e na cadeia produtiva; d) a conjuntura internacional favorável com crescimento da demanda mundial, especialmente no Oriente Médio e na Ásia Oriental. Além disso, o setor de carne de frango brasileiro promove várias ações em parceria com as cadeias produtivas de bovinos e suínos, apoiadas pela Agência Brasileira de Promoção de Exportações e Investimentos (Apex-Brasil) para a prospecção de novos mercados e para a participação em feiras internacionais, como a Gulfood (Emirados Árabes Unidos), Foodex (Japão) e Sial (França).

A produção mundial de carne de frango cresce à taxa média de $4,3 \%$ ao ano, pouco abaixo da nacional em um ponto percentual, atingindo um volume de 75.991 milhões de toneladas em 2010. Os Estados Unidos, a China, o Brasil e a União Europeia destacam-se como os maiores produtores que, no conjunto, representam mais de $60 \%$ da produção mundial. No que se refere às exportações, os Estados Unidos e o Brasil aparecem como os principais ofertantes de carne de frango no mercado mundial, com $72 \%$ do total comercializado em 2010. Já as importações são direcionadas principalmente para o Japão, a Arábia Saudita e a União Europeia. Assim, o mercado mundial de carne de frango tem se caracterizado pelo aumento do consumo devido ao crescimento da demanda, pela preferência da população pela carne branca e pela redução dos preços ocorridos ao longo do tempo devido ao aumento da escala de produção pelos produtores. 


\title{
A chicken network: an analysis of Brazilian and world market from 2002 to 2012
}

\begin{abstract}
The objective of this paper is to analyze the Brazilian and world markets of the chicken from 2002 to 2012. The methodology was a bibliographical research and l descriptive statistical methods. The main results point out that the chicken network is well structured. The domestic production of chicken was concentrated in the states of Rio Grande do Sul, Santa Catarina, Paraná and Sao Paulo, which represents about 70\% of the total. The Brazil was the third largest producer of chickens of the world, sharing $14.1 \%$ and had an average growth rate of $5.3 \%$ per year from 2002 to 2012. The United States were the main world producer, but this country showed a fall in their market share during the same period. The world production of chicken has grown in the average rate of $4.3 \%$ per year. The Brazil and the United States were also major exporters of chicken with $72.0 \%$ of total world market. On the contrary, the consumer market showed a high diversification degree. The three biggest world importers were Japan, Saudi Arabia and the European Union, which represented no more than one fifth of the total. Finally, the increase of chicken consumption tends to be caused by the preference white meat and decrease of its prices. This issue is resulted mainly by technological development, the increase of the production scale of companies and government incentives.
\end{abstract}

Keywords: Chicken network. Domestic market, foreign market, producer.

\section{La cadena de carne de pollo: un análisis de los mercados brasileño y mundial de 2002 a 2012}

\section{Resumen}

El objetivo de este estudio es analizar la evolución de los mercados brasileño y mundial de la carne de pollo en el período de 2002 a 2012, así como analisar las principales características de la carne, su producción, importación y exportación. La metodología utilizada se embaza en los métodos estadísticos y descriptivos. Los resultados apuntan que la cadena es muy estructurada y que la producción nacional de carne de pollo se concentra en los tres estados de la Región Sur y São Paulo, representando alrededor del $70 \%$ del total. Brasil es el tercer mayor productor mundial de pollos, con una cuota de $14,1 \%$ y una tasa promedio anual de crecimiento del $5,3 \%$. Los Estados Unidos aparecen como el principal productor mundial, pero con una disminución de la participación. La producción mundial de la carne de pollo está creciendo, la tasa promedio es de 4,3\% al largo del año. Brasil y Estados Unidos son también los principales exportadores mundiales de carne de pollo, con $72 \%$ del total comercializado. En cambio, los mercados consumidores de carne son muy diversificados y entre los tres principales importadores se destacan el Japonés, Arabia Saudita y Unión Europea, sumando más de un quinto del total. Por último, el aumento del consumo deriva de la preferencia de la población por la carne blanca y la baja de los precios que ocurrieron al largo del tiempo. Este hecho se dio principalmente por el desarrollo tecnológico y por el aumento de escala de producción de las empresas productoras.

Palabras clave: Cadena productiva de la carne de pollo. Análisis del mercado brasileño y mundial. JEL Classification: Q1, Q13, R3, R31 


\section{Notas}

1 Artigo resultante da monografia apresentada para obtenção do grau de bacharel em Ciências Econômicas.

2 Os estudos que tratam de cadeias produtivas, ou especificamente da de frango, são os de Batalha (1997), Braga et al. (2007), Ipardes (2002), Melz (2010), Móri et al. (2011), Oliveira e Gordin (2003), Prochnik e Haguenauer (2001), Triches et al. (2004), Vieira (2011), Vieira, Capacle e Belik (2011), entre outros pesquisadores.

3 Na Tabela 1 do anexo, encontra-se a relação das principais empresas brasileiras exportadoras de frangos no Brasil no período de 2002 a 2010.

4 A Tabela 2 do anexo relaciona os principais estados brasileiros exportadores e sua respectiva participação e taxa média anual de crescimento.

\section{Referências}

ABEF.ASSOCIAÇÃO BRASILEIRA DOS PRODUTORES E EXPORTADORES DE FRANGO. Disponível em: <http://abef.com.br>. Acesso em: 10 maio 2012.

AVEWORLD. Portal da Avicultura Brasileira. Disponível em: <http://www.aveworld.com.br>. Acesso em: 1 set. 2012.

BATALHA, M. O. Gestão agroindustrial: grupo de estudos e pesquisas agroindústrias. São Paulo: Atlas, 1997. Volume I.

BRAGA, N. M.; et al. A cadeia da carne de frango: tensões, desafios e oportunidades. Relatório setorial. Rio de Janeiro: BNDES, 2007.

CASTRO, A. M. G. Prospecção de cadeias produtivas e gestão da informação. 2002. Disponível em: <http://www.mdic.gov.br/tecnoligia/revistas/artigos/SPcamp>. Acesso em: 20 mar. 2012.

FAO. FOOD AND AGRICULTURE ORGANIZATION OF UNITED NATIONS. FAOSTAT Database Collections. Disponível em: <http://faostat.fao.org/site/569/default.aspx\#ancor>. Acesso em: 12 maio 2012.

IPARDES. INSTITUTO PARANAENSE DE DESENVOLVIMENTO ECONÔMICO E SOCIAL. Análise da competitividade da cadeia agroindustrial de carne de frango no estado do Paraná. Curitiba, 2002. Disponível em: <http://www.ipardes.gov.br/>. Acesso em: 12 maio 2012.

MELZ, L. J. Competitividade da cadeia produtiva de carne de frango em Mato Grosso: avaliação dos segmentos de avicultura e processamento. Dissertação (Mestrado em Engenharia de Produção) - Departamento de Engenharia de Produção, Universidade de São Carlos, São Paulo, 2010.

MÓRI, C. et al. Carne de ave separada mecanicamente. Revista Electrónica de Veterinaria REDVET. Espanha, v. VII, n. 04, abr. 2006. 6 p. ISSN 1695-7504. Disponível em: <http://www.veterinaria.org/revistas/redvet/n040406/040602.pdf>. Acesso em 23 out. 2011.

OLIVEIRA, T. C. M. de; GORDIN, M. H. de O. Cadeia produtiva e desenvolvimento local: o caso da carne de frango no Mato Grosso do Sul. 118 f. Dissertação (Mestrado em Desenvolvimento Local) - Programa de Pós-Graduação em Desenvolvimento Local, Universidade Católica Dom Bosco, Campo Grande, 2003.

PROCHNIK, V.;HAGUENAUER, L. Cadeias produtivas e oportunidade de investimento no nordeste brasileiro. Rio de Janeiro: Instituto de Economia, 2001. Texto para discussão no ${ }^{\circ} 53$. 
TRICHES, D. et al. A cadeia produtiva da carne de frango da região da serra gaúcha: uma análise da estrutura de produção e mercado. In: CONGRESSO DA SOCIEDADE BRASILEIRA DE ECONOMIA E SOCIOLOGIA RURAL, 43, 2004, Ribeirão Preto. Anais... Ribeirão Preto: USP, 2004. p. 1-19.

UBA. UNIÃO BRASILEIRA DE AVICULTURA. Disponível em: <http://uba.com.br>. Acesso em: 12 maio 2012.

VIEIRA, A. C. P.; CAPACLE, V. H.; BELIK, W. Estrutura e organização das cadeias produtivas das carnes de frango e bovina no Brasil: reflexões sob a ótica das instituições. 2011. Tese (Doutorado em Economia) - Instituto de Economia, Unicamp, São Paulo, 2011.

VIEIRA, G. A. Análise comparativa da cadeia produtiva do frango de corte na Bahia. 2011. Dissertação (Mestrado em Agronegócio) - Unime, Salvador - BA, 2011. 


\section{Anexo}

Tabela 1 - Empresas produtoras e exportadoras de frango no Brasil no período de 2002 a 2010 (em ton.)

\begin{tabular}{l|l|r|r|r|r|r}
\hline Empresas & \multicolumn{1}{|c|}{ Cidade/Estado } & \multicolumn{1}{c|}{2002} & \multicolumn{1}{c|}{$\%$} & \multicolumn{1}{c|}{2010} & \multicolumn{1}{c}{$\%$} & Var. (\%) * \\
\hline Perdigão & Curitiba/PR & 315.504 & 21,32 & 848.984 & 25,62 & 13,17 \\
Sadia & Curitiba/PR & 367.014 & 24,80 & 816.370 & 24,63 & 10,51 \\
Seara & Seara/SC & 264.163 & 17,85 & 687.546 & 20,75 & 12,70 \\
Frangosul & Jaguará do Sul/SC & 265.459 & 17,94 & 405.346 & 12,23 & 5,43 \\
Big Frango & Rolândia/ PR & 2.330 & 0,16 & 67.402 & 2,03 & 52,29 \\
Copacol & Cafeilândia/PR & 43.750 & 2,96 & 60.725 & 1,83 & 4,18 \\
Aurora & Chapecó/SC & 29.486 & 1,99 & 59.977 & 1,81 & 9,28 \\
Agrovêneto & Nova Veneza/SC & 16.704 & 1,13 & 39.922 & 1,20 & 11,51 \\
Coop. Lar & Matelândia/PR & 24.256 & 1,64 & 37.444 & 1,13 & 5,58 \\
Pif Paf & Palmeiras de Goiás/GO & 2.300 & 0,16 & 12.851 & 0,39 & 23,99 \\
Outros & & 149.034 & 10,05 & 277.433 & 8,38 & 8,08 \\
Total geral & & 1.480 .000 & 100,00 & 3.314 .000 & 100,00 & 10,60 \\
\hline
\end{tabular}

Fonte: Abef (2012).

${ }^{*}$ Refere-se à taxa média geométrica.

Tabela 2 - Estados exportadores de frango no período de 2002 a 2010 (em ton.)

\begin{tabular}{|c|c|c|c|c|c|c|c|}
\hline Estado & 2002 & $\%$ & 2006 & $\%$ & 2010 & $\%$ & Var. (\%) * \\
\hline Santa Catarina & 578.431 & 39,08 & 661.340 & 27,94 & 884.838 & 26,70 & 5,46 \\
\hline Paraná & 327.431 & 22,12 & 655.422 & 27,69 & 867.937 & 26,19 & 12,96 \\
\hline Rio Grande do Sul & 414.035 & 27,98 & 531.865 & 22,47 & 694.283 & 20,95 & 6,67 \\
\hline São Paulo & 37.799 & 2,55 & 168.767 & 7,13 & 231.980 & 7,00 & 25,46 \\
\hline Goiás & 31.329 & 2,12 & 85.212 & 3,60 & 171.002 & 5,16 & 23,63 \\
\hline Mato Grosso & 9.004 & 0,61 & 52.311 & 2,21 & 149.130 & 4,50 & 42,03 \\
\hline Minas Gerais & 39.304 & 2,66 & 90.419 & 3,82 & 142.833 & 4,31 & 17,50 \\
\hline $\begin{array}{l}\text { Mato Grosso do } \\
\text { Sul }\end{array}$ & 28.750 & 1,94 & 82.608 & 3,49 & 114.002 & 3,44 & 18,79 \\
\hline Distrito Federal & 8.540 & 0,58 & 36.215 & 1,53 & 49.047 & 1,48 & 24,42 \\
\hline Outros & 5.377 & 0.36 & 2.841 & 0,12 & 8.948 & 0,27 & 6,57 \\
\hline Total & 1.480 .000 & 100,0 & 2.367 .000 & 100,0 & 3.314 .000 & 100,0 & 10,60 \\
\hline
\end{tabular}

Fonte: Abef (2012).

${ }^{*}$ Refere-se à taxa média geométrica. 